\title{
Heterogeneous Catalysis Experiments at XFELs. Are we Close to Producing a Catalysis Movie?
}

\author{
Jacinto Sá · Jakub Szlachetko
}

Received: 18 November 2013/Accepted: 21 November 2013/Published online: 17 December 2013

(C) The Author(s) 2013. This article is published with open access at Springerlink.com

\begin{abstract}
The advent of X-ray free electron lasers enabled scientist to achieve the goal of producing a movie of a catalytic transformation. This perspective highlights the technical developments both on facilities and X-ray spectroscopy that brought us a bit closer to attain the main goal. However there are a couple of issues that need to be solve, namely sample stability and selective triggering.
\end{abstract}

Keywords Heterogeneous catalysis - XFEL - Catalytic movie $\cdot$ High-resolution X-ray spectroscopy

Scientists working in the field of catalysis are fascinated with the prospect of producing a movie portraying a catalytic transformation. The enthrallment with movie making has been enticed both by the technical challenges that need to be overcome and the unprecedented access to the fundamental traits of a catalytic reaction. The importance in accessing fundamental understanding of catalysis was masterfully highlighted on the 2007 report from the US Department of Energy Basic Energy Sciences Workshop [1] in 'to realize the full potential of catalysis for energy applications, scientists must develop a profound understanding of catalytic transformations so that they can design and build effective catalysts with atom-by-atom

J. Sá (ه) · J. Szlachetko

Paul Scherrer Institute, 5232 Villigen, Switzerland

e-mail: jacinto.sa@psi.ch

J. Szlachetko

e-mail: jakub.szlachetko@psi.ch

J. Szlachetko

Institute of Physics, Jan Kochanowski University, 25-406 Kielce,

Poland precision and convert reactants to products with molecular precision. Moreover, they must build tools to make realtime, spatially resolved measurements of operating catalysts. Ultimately, scientists must use these tools to achieve a fundamental understanding of catalytic processes occurring in multiscale, multiphase environments'. As reminder catalysis is a trillion-dollar industry [2], involve in $90 \%$ of all commercially produced chemical products [3].

Catalysis is driven by the electronic structure of the valence shell. The availability of valence orbitals to form chemical bonds, and thus taking part in the catalytic reaction depends on their electron occupancy and energy [4-8]. Hard X-rays are ideal probes since they possess high penetration depth and are element specific, which enables the identification of chemical states under working conditions [9, 10]. X-ray photon-in photon-out core level spectroscopy is a powerful tool to understand catalytic reactions because it enables us to map the entire electronic structure of the catalyst under catalytic relevant conditions.

The development of hard X-ray free electron lasers (XFELs) revolutionized the field of ultrafast time-resolved X-ray measurements [11-13]. FLASH VUV-soft XFEL located at DESY in Hamburg [14, 15] was the prototype for this kind of facilities that was shortly followed by the linac coherent light source (LCLS) (Stanford, USA), the first operational hard X-ray free electron laser [16]. LCLS operates both in the soft X-ray and hard X-ray regimes, with experimental stations dedicated to various fields of research [17]. SACLA XFEL facility at SPring-8 in Japan started operation recently [18, 19], and several XFEL projects are underway worldwide, including machines in Germany [20], South Korea [21], and Switzerland [22].

$\mathrm{X}$-ray free electron lasers sources consist of high-energy $(\mathrm{GeV})$ electron bunches injected into a series of undulators that are hundreds to thousands of meters long. The 
oscillation of the electrons in the initial part of the undulators causes radiation to be emitted, as in a synchrotron. As the radiation and electrons co-propagate the radiation field builds up and the electrons start to interact with the radiation, causing a micro-bunch structure to appear with the wavelength of the radiation. This micro-bunch structure radiates coherent $\mathrm{X}$-ray photons, the intensity of which builds up exponentially in a process called self-amplified spontaneous emission (SASE). The result is an intense, spatially coherent beam of femtosecond X-ray pulses, which can be used for experiments.

The spontaneous nature of the SASE process generates XFELs radiation with a large variance in pulse energy (photon flux), photon energy (spectrum), and pulse arrival time. The result is large pulse-to-pulse parameter fluctuation. There are several approaches to reduce XFEL beam instability at the sample position, the most promising approach being to seed the XFEL, preferentially selecting a portion of the photon spectrum to initiate the lasing process [23], resulting in a significant improvement in the spectral stability with a small cost in photon flux (factor of approximately 5-10) [24]. Though the seeded X-ray spectrum is not properly monochromatic, as it has a tail that extends a few $\mathrm{eV}$ to lower photon energies, it greatly enhances the pulse-to-pulse energy stability of the photon beam through a monochromator. The recent introduction of a 'timing tool' $[25,26]$, which measures the timing jitter between the optical laser and the XFEL, enabled measurements with $10 \mathrm{fs}$ time resolution [27]. This development has catapulted XFEL pump-probe measurements into time domains previously only accessible with ultrafast optical laser system.

The principal feature of a XFEL is the mammoth number of photons (1,011-1,012 photons/pulse) in a pulse with durations of 10-100 fs, or even sub-fs [28], rendering their X-ray peak brilliance unrivaled. Both SACLA and LCLS operate at low repetition rates of $100-120 \mathrm{~Hz}$, which makes their average X-ray flux similar to that of 3rd-generation synchrotron facilities. The experiments that have benefitted the most from the development of XFEL facilities have been those that either take advantage of the large number of photons per pulse to perform single-shot or nonlinear X-ray experiments, or those that take advantage of the ultrashort pulse durations to perform measurements on the femtosecond timescale. For example, crystallography takes advantage of the fact that ultrashort X-ray pulse can outrun crystal damage, the so called diffraction before destruction approach $[29,30]$.

Proof-of-concept femtosecond time-resolved X-ray spectroscopy measurements have been performed, in which the authors detected the first steps in hot electron-mediated catalysis [31] and surface bond breaking [32]. Resonant $\mathrm{X}$-ray emission spectroscopy (RXES) monitors the occupied electronic states involved in a chemical reaction [33]. The technique can be carried out on a shot-to-shot basis if one uses a dispersive spectrometer, such as von Hamos [34]. Unoccupied density of states can be determined by means of X-ray absorption spectroscopy (XAS). The advent of high resolution XAS (HR-XAS) enabled determination of changes in the unoccupied density states caused not only by metal oxidation state but also due to the presence, identity and adsorption strength of chemisorbed species [35-37]. However HR-XAS has a serious limitation arising from the fact that XAS measurements require scanning of the incoming energy, limiting the time resolution at synchrotrons to the speed at which the monochromator can be moved, i.e., HRXAS cannot be performed on a shot-to-shot, which is XFELs desired mode.

This limitation was mitigated by Szlachetko et al. [38], which demonstrated that high-energy resolution off-resonant spectroscopy (HEROS) could provide element-specific information about the unoccupied density of states. The concept of HEROS is depicted in Fig. 1. Due to the scanning free arrangement, the HEROS spectra can be recorded on a shot-to-shot basis, while maintaining an energy resolution independent of the initial lifetime broadening [39]. Moreover, the self-absorption process does not affect HEROS spectra, thus making it a powerful technique to identify and quantify the desired structural changes during a catalytic reaction.

The HEROS spectroscopy is based on the second-order photon-atom interaction [40, 41]. As noted by Tulkki and Aberg [40] in their theoretical work describing the resonant $\mathrm{X}$-ray Raman scattering process, for incident beam energies tuned far below the absorption edge (off-resonant regime), the shape of the X-ray emission spectrum (XES) is proportional to the unoccupied electronic states multiplied by a Lorentz function resulting from core-hole broadening. In other words, for off-resonant spectroscopy the XAS spectrum is directly reflected in XES at one excitation energy. Until nowadays, the potential for extracting the electronic structure from a single X-ray emission spectrum recorded at off-resonant excitations was not explored because of the extremely weak scattering cross section as compared to X-ray absorption spectroscopy [42-45]. With advent of XFELs, the low scattering cross sections are compensated by large intensity of femtosecond X-ray pulses. Moreover, in comparison to synchrotron sources where typically scanning-type spectrometers are employed for measurements, the application of dispersive-type spectrometers at XFELs is essential. The dispersion provides a unique possibility to record broadband energies in a single acquisition and thus facilitate experiments in terms of signal normalization.

As an example, we show the HEROS spectra recorded for nano-Pt/Al2O3 in different gas environment (i.e. $\mathrm{H}_{2}$ 
Fig. 1 Schematic

representation (a) and energy level drawing (b) for an offresonant scattering process. Reproduced from Szlachetko et al. [38]

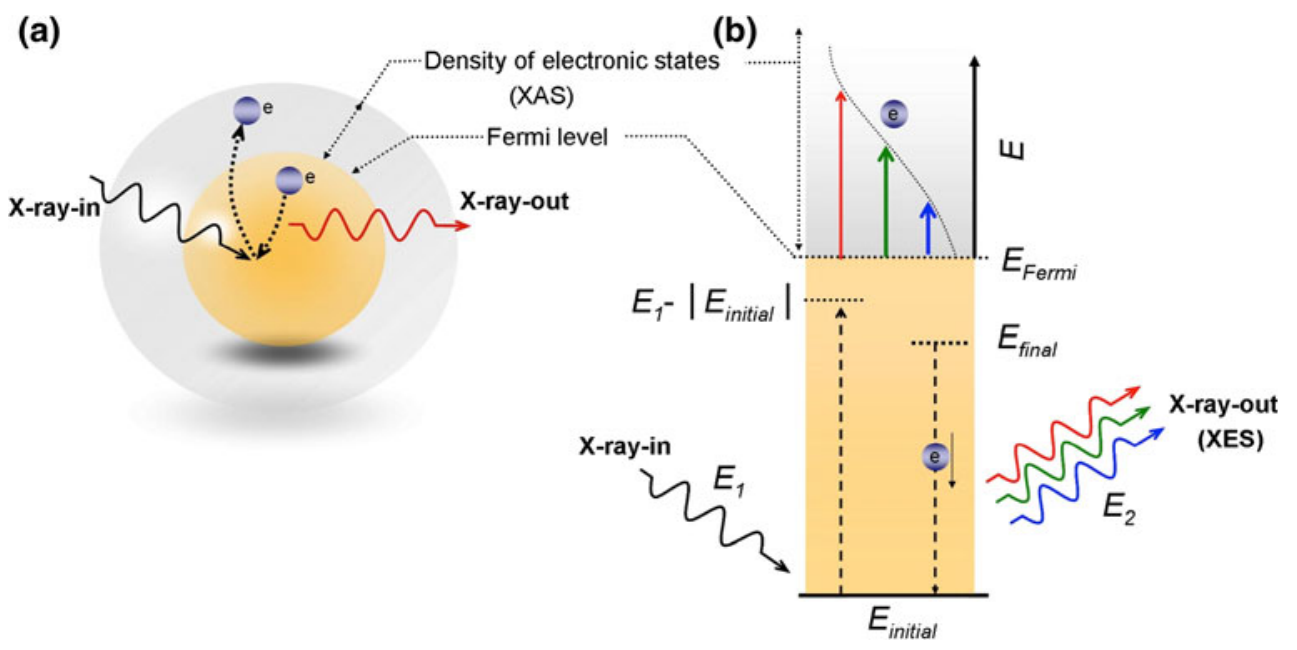

and $\mathrm{CO}$ at $200{ }^{\circ} \mathrm{C}$ ). The sample consisted of 3-4 nm Pt nanoparticles supported on alumina (surface area $150 \mathrm{~m}^{2} /$ g). The metal loading is $1 \mathrm{wt} \%$ and the catalyst was reduced at $200{ }^{\circ} \mathrm{C}$ in pure $\mathrm{H}_{2}$ for $1 \mathrm{~h}$ before the experiments. The experimental spectra are compared to the theoretical ones calculated using a combination of FEFF code with scattering formulas developed by Tulkki and Aberg. Figure 2 demonstrates the sensitivity of HEROS spectroscopy on catalytic system under in situ conditions. Because of experimental resolution being independent on initial core-hole broadening, the HEROS provide enhanced spectral features, as HR-XAS, however without necessity of scanning the incident beam energy. Thus the metal-site electronic structure changes induced by binding molecules can be detected on a shot-to-shot basis measurement. We would like to stress here, that the chemical speciation by HEROS might be performed using the same strategies as for XAS measurements. On one side a set of reference spectra can be measured that can later be used to identify chemical composition of matter under working conditions. Complementary to reference data, calculations using common XAS codes like FEFF [46-49], Orca [50-52] or FDMNES [53-55] can be used to support the experimental data.

As aforementioned, X-ray emission spectroscopy (XES) is an element-specific technique that provides access to the occupied electronic structure of scattering atom [56-59]. XES relies on a second-order scattering process, where the core-electron is ejected into the continuum and an electron from higher electronic levels subsequently fills the remaining core-hole with simultaneous X-ray emission. The emitted X-ray energy is specific for the scattering atom as well as for the involved atomic levels. In general, XES may be employed for detection of core-to-core (c2c) or valence-to-core (v2c) transitions, which involve deep lying electronic states or outermost valence electrons, respectively. Figure 3 depicts the principal of c2c-XES and v2c-

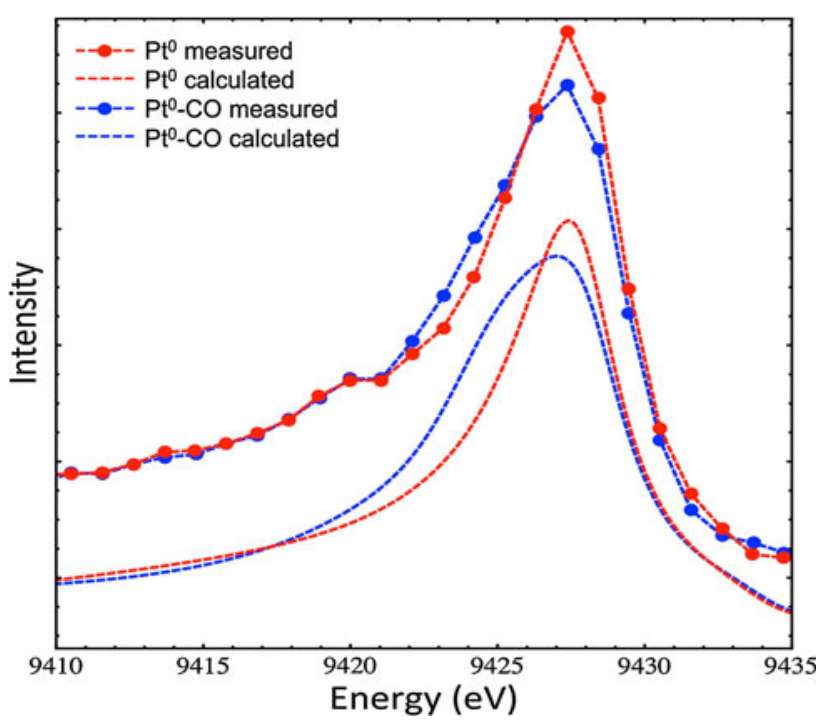

Fig. 2 In-situ HEROS spectra of nanoPt/ $\mathrm{Al}_{2} \mathrm{O}_{3}$ at $200{ }^{\circ} \mathrm{C}$ in $\mathrm{H}_{2}($ red $)$ and $\mathrm{CO}$ (blue)

XES. The c2c-XES is commonly employed in combination with X-ray absorption spectroscopy because of relatively high decay rates [60-63]. The core electronic states are usually weakly interacting with the outermost electrons leading to a simple description of the initial and final configurations. The c2c-XES can be used as a probe of inner shell electron correlations, multi-electron scattering and electron rearrangement processes [64-68]. The v2ctransitions are much weaker but on the other hand provide sensitivity to the chemical surrounding of the scattering atom, and in particular allow probing the ligand orbitals. The v2c transition involves the valence electrons decay into the core-hole and therefore for mapping of the highest occupied electronic states in the system. Comparing to the electron based techniques commonly used for determination of low energy electronic states, v2c-XES uses a 


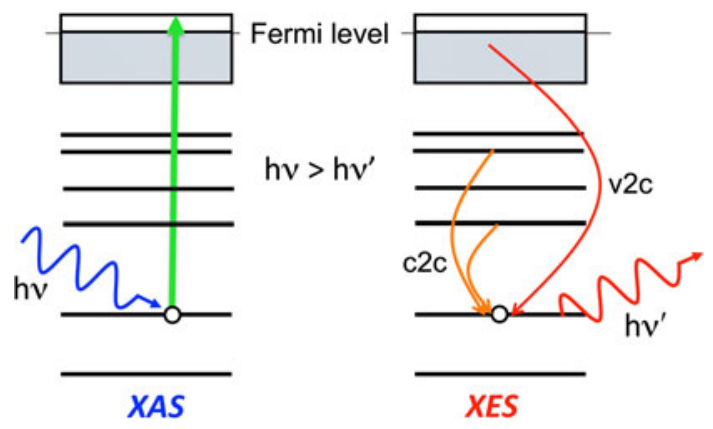

Fig. 3 Atomic process of XAS, v2c-XES and c2c-XES

few keV X-ray energies for incoming and emitted photons. Thanks to the penetrating properties of hard X-rays, the occupied states and ligand environment may be thus probed in the bulk materials, or matter under working conditions.

As an example, the XES spectrum of $\mathrm{CuO}$ powder is presented in Fig. 4. The $\mathrm{CuO}$ was purchased from Aldrich and used as received. The main emission lines, involving $\mathrm{L}$ and $\mathrm{M}$ final core states as well as v2c transitions, are plotted in black, red and blue lines respectively. As shown the transition yields vary depending on the final electronic state. For core-to-core transitions, strong X-ray emission lines are detected, however those are usually insensitive to the chemical environment of scattering atom. On the other hand, the v2c transitions are used as a direct probe of the valence electron configuration with enhanced sensitivity to ligands [69], however with yields of few hundreds lower than the main XES lines. We should note here, that in contrast to the HEROS technique, XES does not require monochromatic beams, thus may be simply applied with SASE incident beams delivered by the XFELs.

It worth mentioning that HEROS and RXES are bulk techniques, however there are several strategies to retrieve information exclusively from the surface. The most

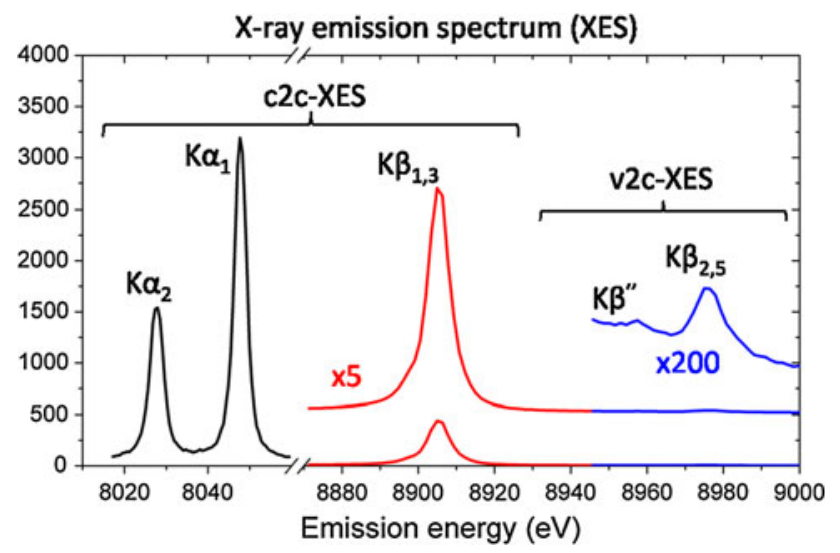

Fig. 4 The c2c and v2c-XES spectrum of $\mathrm{CuO}$ successful approach is to apply phase or frequency modulations methodologies, which changes the surface chemistry while the bulk remains unalterable [70-72].

The arrival of XFELs offered researchers sufficient time resolution to follow a catalytic reaction in real time, i.e., produce 'movies' of a catalytic transformation. This is conceptually achieved using pump-probe methodology [73]. Briefly, the reaction is initiated with an external trigger (time zero), and the changes are monitored with $\mathrm{X}$-ray probe pulses delayed in time in respect to the trigger. The methodology enables acquisition of 'snapshots' during a catalytic transformation, which are then stitched together to make the movie. Despite the strides made towards ensuring a successful XFEL experiment, there are a couple of hurdles yet to be taken, concerning selective triggering and sample stability. Fine-grained control over all experiments parameters is paramount since XFELs experiments are dedicated to a single user at a time with limited access to measurement time at these facilities.

The trigger, used to initiate/excite the system, should create a unique excited-state potential surface characteristic of a single catalytic transformation. Conventionally, optical femtosecond pulses are used to initiate and/or excite a particular system. There are a few catalytic systems that may be triggered using optical pulses, among them the charge separation on photo-catalysis. However the vast majority of heterogeneous catalytic systems cannot be triggered by means of a simple optical excitation primarily due to reaction complexity and/or absence of specific modes on a heterogeneous catalyst or reactant that can be optically excited. A possible strategy is to use multi-pulses or shaped femtosecond pulses, which have to be optimized prior to experiment at the XFEL. Nuernberger et al. [74] demonstrated that the catalytic bond formation could be affected with a shaped femtosecond but the strategy has not been further pursued. Other possible triggers are laserinduced temperature jumps or the strong electric field of $\mathrm{THz}$ radiation [75]. However, it needs to be demonstrated that those triggers possess the required specificity and selectivity. Furthermore these are inherently picosecond triggers that will decrease the overall time resolution. As aforementioned, HEROS and RXES are bulk techniques, however the ability to trigger selectively a catalytic process converts them into surface techniques since excited data is subtracted from non-excited in pump-probe methodology.

Samples stability is another major issue. Figure 5 shows what happens to $\mathrm{Cu}$ foil during XFEL measurement at LCLS. Within the measurement, the $\mathrm{Cu}$ foil gets sputtered, requiring the sample position to be refreshed every minute. The use of short probe pulses enables the acquisition of desired data before sample damage [76-78]. However, this also means that the sample needs to be refreshed continuously. For liquid phase transformations, the solution seems 


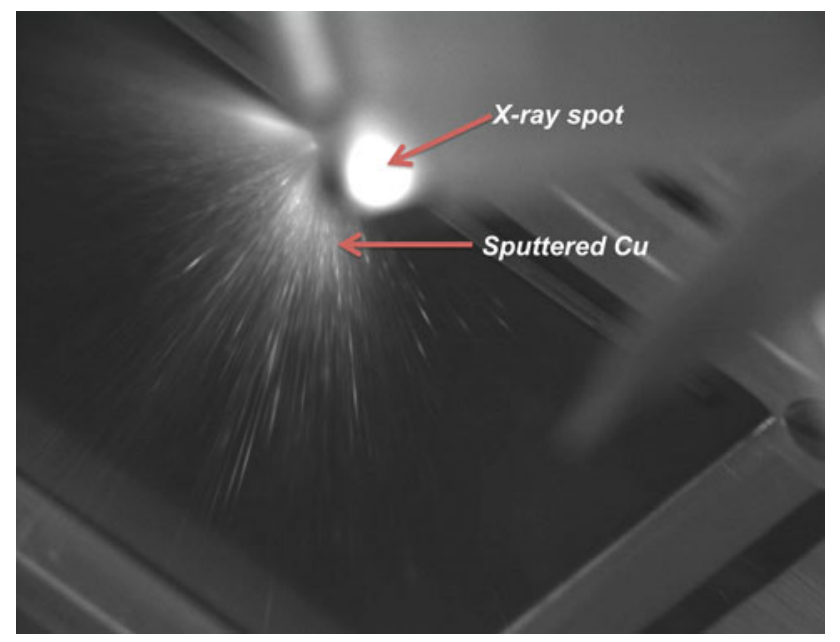

Fig. 5 Image depicting sputtering of $\mathrm{Cu}$ foil at LCLS/SLAC, experiment L618, CIX FEL beam line, 2012-12-15

to be the use of micro/nano liquid jets [79-81]. This might work for some of the liquid phase transformations but cannot be adapted for gas phase transformations, which accounts for a large number of heterogeneous catalytic transformations. The problem is further exacerbated with the decrease of incoming energy since the penetration depth decreases, i.e., more photons get absorbed.

A promising technology is a freestanding particles delivery system using aerodynamic focusing methods. It has been demonstrated that such a set up is able to deliver aerosols, nanoparticles, viruses, cells, and biomolecules from ambient conditions into vacuum [82-84]. Liu et al. $[85,86]$ designed an apparatus that uses in-line thin plate orifices to manipulate the particle lateral spatial distribution prior to them passing through the nozzle and subsequently undergoing supersonic expansion into vacuum. An axisymmetric stack of these thin plate orifices, or aerodynamics lenses, provides successive contractions of a flowing particle beam cross section and enables focusing of a wide range of particles $(1 \mathrm{~nm}$ to $10 \mu \mathrm{m})$ [87]. Equipped with a pressure reducer, the inlet of the aerodynamic lenses stack samples aerosolized particles from atmospheric pressure at a rate of ca. $1 \mathrm{~L} / \mathrm{min}$ and injects them into vacuum $\left(<10^{-6} \mathrm{mbar}\right)$. If the laser diameter is similar to the one used by single particle aerosol mass spectroscopy [88, 89], a particle moving at $150 \mathrm{~m} / \mathrm{s}$ will have an effective interaction time of a few microseconds, thus enabling single catalytic events to take place. Bogan et al. [90] used this technology to acquire the diffraction of iron oxide ellipsoid nanoparticles with dimensions of $200 \mathrm{~nm}$ by $50 \mathrm{~nm}$, thus confirming the applicability of this technology to deliver nano-catalysts into a measuring chamber. The iron oxide nanoparticles were dispersed in water and injected into vacuum.
Cryogenic cooling has been used at synchrotrons to minimize/prevent beam damage, and in principle can be used at XFELs. However this is not a universal solution since most catalytic systems are only active at high temperatures (above liquid $\mathrm{N}_{2}$ temperatures). Another option is to use absorbers that decrease the number of photons at the sample per pulse, leading to a decrease of XFEL pulse brilliance. This is not desirable for X-ray diffraction or scattering experiments in which every photon counts, but might be a valid option for X-ray spectroscopy since the $\mathrm{X}$-ray photons absorption is roughly an order of magnitude higher than photon scattering [78].

Though 4th-generation light sources are in its infancy, it is clear that their effect on the field of time-resolved X-ray science will be profound and far-reaching. In the case of heterogeneous catalysis, XFELs may enable us to follow reaction in real time, however in order to do so, problems with selective triggering and sample stability have to be solved, in particular for gas phase reactions characterized by multiple reaction steps. In a cinematographic analogy, we have the camera, the set, the script and the actors; what is missing is the director to shout 'action' and direct the scenes, and that the actors do not fall ill.

We would like finish with a word of caution to scientists aiming to take advantage of XFELs capabilities. Experiments at XFELs are inherently different from experiments at synchrotrons. While test experiments at synchrotrons are useful and in some cases necessary to confirm experimental aspects such as feasibility, the experiments at synchrotrons cannot be seen as a pre-run to the XFELs experiments because there is a plethora of parameters that are unique to XFELs. These parameters should be carefully considered before any experiment, follow-up proposals are often rejected due to the limited operational beam time.

Acknowledgments We would like to acknowledge everybody that took part of the LCLS/SLAC, Experiment L618, CIX FEL beam line and proof-of-concept experiments at SuperXAS (X10DA) beam line of the Swiss Light Source (SLS), in particular Dr. C. Milne \& Dr. M. Nachtegaal (PSI) and Prof. J.-C. Douse \& group. The authors also acknowledge LCLS/SLAC and SLS/PSI for access to facilities.

Open Access This article is distributed under the terms of the Creative Commons Attribution License which permits any use, distribution, and reproduction in any medium, provided the original author(s) and the source are credited.

\section{References}

1. http://web.anl.gov/catalysis-science/publications/CAT_rpt.pdf. Accessed: 2013-12-09

2. http://www.climatetechnology.gov/library/2005/tech-options/ tor2005-143.pdf. Accessed: 2013-12-09

3. 'Recognizing the Best in Innovation: Breakthrough Catalyst', R\&D Magazine, September 2005, p. 20 
4. Hammer B, Nørskov JK (1995) Nature 376:238

5. Hammer B, Nørskov JK (2000) Adv Catal 45:71

6. Lima FHB, Zhang J, Shao MH, Sasaki K, Vukmirovic MB, Ticianelli EA, Adzic RR (2007) J Phys Chem C 111:404

7. Heiz U, Bullock EL (2004) J Mater Chem 14:564

8. Sameera WMC, Maseras F (2012) WIREs Comput Mol Sci 2:375

9. Tada M, Murata S, Asakoka T, Hiroshima K, Okumura K, Tanida H, Uruga T, Nakanishi H, Matsumoto S-I, Inada Y, Nomura M, Iwasawa Y (2007) Angew Chem Int Ed 46:4310

10. Zhang J, Sasaki K, Sutter E, Adzic RR (2007) Science 315:220

11. Barletta WA, Bisognano J, Corlett JN, Emma P, Huang Z, Kim K, Lindberg R, Murphy JB, Neil GR, Nguyen DC, Pellegrini C, Rimmer RA, Sannibale F, Stupakov G, Walker RP, Zholents AA (2010) Nucl Instrum Meth A 618:69

12. Pellegrini C (2010) The next generation of X-ray sources. Reviews Accelerator Sci Technol 3:185-202

13. Sonntag B (2001) Nucl Instrum Meth A 467-468:8

14. Voitkiv AB, Ullrich V, Bostedt C, Chapman H, Costello J, Crespolopezurrutia J, Dusterer S, Epp SW, Feldhaus J, Fohlisch A, Meyer M, Moller T (2009) Nucl Instrum Meth A 601:108

15. Tiedtke K, Azima A, von Bargen N, Bittner L, Bonfigt S, Düsterer S, Faatz B, Frühling U, Gensch M, Gerth C, Guerassimova N, Hahn U, Hans T, Hesse M, Honkavaar K, Jastrow U, Juranic P, Kapitzki S, Keitel B, Kracht T, Kuhlmann M, Li WB, Martins M, Núñez T, Plönjes E, Redlin H, Saldin EL, Schneidmiller EA, Schneider JR, Schreiber S, Stojanovic N, Tavella F, Toleikis S, Treusch R, Weigelt H, Wellhöfer M, Wabnitz H, Yurkov MV, Feldhaus J (2009) New J Phys 11:023029

16. Emma P, Akre R, Arthur J, Bionta R, Bostedt C, Bozek J, Brachmann A, Bucksbaum P, Coffee R, Decker F-J, Ding Y, Dowell D, Edstrom S, Fisher A, Frisch J, Gilevich S, Hastings J, Hays G, Hering Ph, Huang Z, Iverson R, Loos H, Messerschmidt M, Miahnahri A, Moeller S, Nuhn H-D, Pile G, Ratner D, Rzepiela J, Schultz D, Smith T, Stefan P, Tompkins H, Turner J, Welch J, White W, Wu J, Yocky G, Galayda J (2010) Nat Photon 4:641

17. LCLS: http://lcls.slac.stanford.edu. Accessed: 2013-10-01

18. Ishikawa T, Aoyagi H, Asaka T, Asano Y, Azumi N, Bizen T, Ego H, Fukami K, Fukui T, Furukawa Y, Goto S, Hanaki H, Hara T, Hasegawa T, Hatsui T, Higashiya A, Hirono T, Hosoda N, Ishii $\mathrm{M}$, Inagaki $\mathrm{T}$, Inubushi $\mathrm{Y}$, Itoga $\mathrm{T}$, Joti $\mathrm{Y}$, Kago $\mathrm{M}$, Kameshima T, Kimura H, Kirihara Y, Kiyomichi A, Kobayashi T, Kondo C, Kudo T, Maesaka H, Maréchal XM, Masuda T, Matsubara S, Matsumoto T, Matsushita T, Matsui S, Nagasono M, Nariyama N, Ohashi H, Ohata T, Ohshima T, Ono S, Otake Y, Saji C, Sakurai T, Sato T, Sawada K, Seike T, Shirasawa K, Sugimoto T, Suzuki S, Takahashi S, Takebe H, Takeshita K, Tamasaku K, Tanaka H, Tanaka R, Tanaka T, Togashi T, Togawa K, Tokuhisa A, Tomizawa H, Tono K, Wu S, Yabashi M, Yamaga M, Yamashita A, Yanagida K, Zhang C, Shintake T, Kitamura H, Kumagai N (2012) Nat Photon 6:540

19. Pile D (2011) X-rays: first light from SACLA. Nat Photon 5:456-457

20. European XFEL project: http://www.xfel.eu/. Accessed: 2013-09-29

21. PAL XFEL Project: http://pal.postech.ac.kr/paleng/. Accessed: 2013-09-29

22. SwissFEL website: http://www.swissfel.ch/. Accessed: 2013-0914

23. Geloni G, Kocharyan V, Saldin E (2011) J Mod Optic 58:1391

24. Amann J, Berg W, Blank V, Decker F-J, Ding Y, Emma P, Feng Y, Frisch J, Fritz D, Hastings J, Huang Z, Krzywinski J, Lindberg R, Loos H, Lutman A, Nuhn H-D, Ratner D, Rzepiela J, Shu D, Shvyd'ko Yu, Spampinati S, Stoupin S, Terentyev S, Trakhtenberg E, Walz D, Welch J, Wu J, Zholents A, Zhu D (2012) Nat Photon 6:693
25. Beye M, Krupin O, Hays G, Reid AH, Rupp D, de Jong S, Lee S, Lee W-S, Chuang Y-D, Coffee R, Cryan JP, Glownia JM, Föhlisch A, Holmes MR, Fry AR, White WE, Bostedt C, Scherz AO, Durr HA, Schlotter WF (2012) Appl Phys Lett 100:121108

26. Bionta MR, Lemke HT, Cryan JP, Glownia JM, Bostedt C, Cammarata M, Castagna J-C, Ding Y, Fritz DM, Fry AR, Krzywinski J, Messerschmidt M, Schorb S, Swiggers ML, Coffee RN (2011) Opt Express 19:21855

27. Harmand M, Coffee R, Bionta MR, Chollet M, French D, Zhu D, Fritz DM, Lemke HT, Medvedev N, Ziaja B, Toleikis S, Cammarata M (2013) Nat Photon 7:215

28. V. Wacker, Y. Ding, J. Frisch, Z. Huang, C. Pellegrini, F. Zhou, (2012) Proceedings of FEL2012, Nara, Japan. 2012606

29. Chapmann HN, Barty A, Bogan MJ, Boutet S, Frank M, HauRiege SP, Marchesini S, Woods BW, Bajt S, Benner WH, London RA, Plönjes E, Kuhlmann M, Treusch R, Düsterer S, Tschentscher T, Schneider JR, Spiller E, Möller T, Bostedt C, Hoener M, Shapiro DA, Hodgson KO, van der Spoel D, Burmeister F, Bergh M, Caleman C, Huldt G, Seibert MM, Maia FRNC, Lee RW, Szöke A, Timneanu N, Hajdu J (2006) Nat Phys 2:839

30. Chapman HN, Fromme P, Barty A, White TA, Kirian RA, Aquila A, Hunter MS, Schulz J, DePonte DP, Weierstall U, Doak RB, Maia FRNC, Martin AV, Schlichting I, Lomb L, Coppola N, Shoeman RL, Epp SW, Hartmann R, Rolles D, Rudenko A, Foucar L, Kimmel N, Weidenspointner G, Holl P, Liang M, Barthelmess M, Caleman C, Boutet S, Bogan MJ, Krzywinski J, Bostedt C, Bajt S, Gumprecht L, Rudek B, Erk B, Schmidt C, Hömke A, Reich C, Pietschner D, Strüder L, Hauser G, Gorke H, Ullrich J, Herrmann S, Schaller G, Schopper F, Soltau H, Kühnel K-U, Messerschmidt M, Bozek JD, Hau-Riege SP, Frank M, Hampton CY, Sierra RG, Starodub D, Williams GJ, Hajdu J, Timneanu N, Seibert MM, Andreasson J, Rocker A, Jönsson O, Svenda M, Stern S, Nass K, Andritschke R, Schröter C-D, Krasniqi F, Bott M, Schmidt KE, Wang X, Grotjohann I, Holton JM, Barends TRM, Neutze R, Marchesini S, Fromme R, Schorb S, Rupp D, Adolph M, Gorkhover T, Andersson I, Hirsemann H, Potdevin G, Graafsma H, Nilsson B, Spence JCH (2011) Nature 469:73

31. Beye M, Anniyev T, Coffee R, Dell'Angela M, Föhlisch A, Gladh J, Katayama T, Kaya S, Krupin O, Møgelhøj A, Nilsson A, Nordlund D, Nørskov JK, Öberg H, Ogasawara H, Pettersson LGM, Schlotter WF, Sellberg JA, Sorgenfrei F, Turner JJ, Wolf M, Wurth W, Öström H (2013) Phys Rev Lett 110:186101

32. Dell'Angela M, Anniyev T, Beye M, Coffee R, Föhlisch A, Gladh J, Katayama T, Kaya S, Krupin O, LaRue J, Møgelhøj A, Nordlund D, Nørskov JK, Öberg H, Ogasawara H, Öström H, Pettersson LGM, Schlotter WF, Sellberg JA, Sorgenfrei F, Turner JJ, Wolf M, Wurth W, Nilsson A (2013) Science 339:1302

33. Vankó G, Neisius T, Molnár G, Renz F, Kárpáti S, Shukla A, de Groot FMF (2006) J Phys Chem B 110:11647

34. Szlachetko J, Nachetgaal M, de Boni E, Safonova O, Sá J, Smolentsev G, Szlachetko M, van Bokhoven JA, Dousse J-C, Hoszowska J, Kayser Y, Jagodzinski P, Bergamaschi A, Schmid B, David C, Lücke A (2012) Rev Sci Instrum 83:103105

35. Friebel D, Miller DJ, Nordlund D, Ogasawara H, Nilsson A (2011) Angew Chem 123:10372

36. Friebel D, Viswanathan V, Miller DJ, Anniyev T, Ogasawara H, Larsen AH, O’Grady CP, Nørskov JK, Nilsson A (2012) J Am Chem Soc 134:9664

37. Manyar HG, Daly H, Moor H, McMonagle S, Tao Y, Goguet A, Yadav GD, Sá J, Szlachetko J, Hardacre C (2013) Catal Sci Technol 3:1497

38. Szlachetko J, Nachtegaal M, Sá J, Dousse J-C, Hoszowska J, Kleymenov E, Janousch M, Safonova OV, van Bokhoven JA (2012) Chem Commun 48:10898 
39. Szlachetko J, Milne CJ, Hoszowska J, Dousse J-C, Błachucki W, Sá J, Kayser Y, Messerschmidt M, Abela R, Boutet S, David C, Williams G, Pajek M, Patterson B, Smolentsev G, van Bokhoven JA, Nachtegaal M (submitted) Struct Dyn

40. Tulkki J, Aberg T (1982) J Phys B Mol Opt 15:L435

41. Tulkki J (1983) Phys Rev A 27:3375

42. Hayashi H, Takeda R, Udagawa Y, Nakamura T, Miyagawa H, Shoji H, Nanao S, Kawamura N (2003) Phys Rev B 68:45122

43. Szlachetko J, Dousse JC, Hoszowska J, Pajek M, Barrett R, Berset M, Fennane K, Kubala-Kukus A, Szlachetko M (2006) Phys Rev Lett 97:073001

44. Szlachetko J, Dousse JC, Berset M, Fennane K, Szlachetko M, Hoszowska J, Barrett R, Pajek M, Kubala-Kukus A (2007) Phys Rev A 75:022512

45. Kavčič M, Žitnik M, Bučar K, Mihelič A, Marolt B, Szlachetko J, Glatzel P, Kvashnina K (2013) Phys Rev B 87:075106

46. Ankudinov AL, Ravel B, Rehr JJ, Conradson SD (1998) Phys Rev B 58:7565

47. Ankudinov AL, Rehr JJ, Low J, Bare SR (2001) Phys Rev Lett $86: 1642$

48. Safonova OV, Tromp M, van Bokhoven JA, de Groot FMF, Evans J, Glatzel P (2006) J Phys Chem B 110:16162

49. Sá J, Szlachetko J, Sikora M, Kavčič M, Nachtegaal M (2013) Nanoscale 5:8462

50. http://cec.mpg.de/forum/. Accessed: 2013-12-09

51. Sarangi R, Aboelella N, Fujisawa K, Tolman WB, Hedman B, Hodgson KO, Solomon EI (2006) J Am Chem Soc 128:8286

52. Yano J, Robblee J, Pushkar Y, Marcus MA, Sauer K, Bendix J, Collins TJ, Solomon EI, DeBeer George S, Yachandra V (2007) J Am Chem Soc 129:12989

53. http://neel.cnrs.fr/spip.php?rubrique1007\&lang=en. Accessed: 2013-12-09

54. Joly Y (2001) Phys Rev B 63:125120

55. Sá J, Tagliabue G, Friedli P, Szlachetko J, Rittmann-Frank MH, Santomauro FG, Milne CJ, Sigg H (2013) Energy Environ Sci $6: 3584$

56. Bergmann U, Glatzel P (2009) Photosynth Res 102:255

57. Lancaster KM, Roemelt M, Ettenhuber P, Hu Y, Ribbe MW, Neese F, Bergmann U, DeBeer S (2011) Science 334:974

58. Szlachetko J, Banas D, Kubala-Kukus A, Pajek M, Cao W, Dousse JC, Hoszowska J, Kayser Y, Szlachetko M, Kavčič M, Salome M, Susini J (2009) J Appl Phys 105:086101

59. Alonso-Mori R, Kern J, Gildea RJ, Sokaras D, Weng TC, Lassalle-Kaiser B, Tran R, Hattne J, Laksmono H, Hellmich J, Glockner C, Echols N, Sierra RG, Schafer DW, Sellberg J, Kenney C, Herbst R, Pines J, Hart P, Herrmann S, Grosse-Kunstleve RW, Latimer MJ, Fry AR, Messerschmidt MM, Miahnahri A, Seibert MM, Zwart PH, White WE, Adams PD, Bogan MJ, Boutet S, Williams GJ, Zouni A, Messinger J, Glatzel P, Sauter NK, Yachandra VK, Yano J, Bergmann U (2012) Proc Natl Acad Sci USA 109:19103

60. Singh J, Lamberti C, van Bokhoven JA (2010) Chem Soc Rev 39:4754

61. Szlachetko J, Sá J, Safonova OV, Smolentsev G, Szlachetko M, van Bokhoven JA, Nachtegaal M (2013) J Electron Spectrosc Relat Phenom 188:161

62. Glatzel P, Sikora M, Eeckhout S, Safonova OV, Smolentsev G, Pirngruber G, van Bokhoven JA, Grunewaldt JD, Tromp M (2007) AIP CP879:1731

63. Glatzel P, Bergmann U, de Groot FMF, Weckhuysen BM, Cramer SP (2005) Phys Scripta T115:1032

64. Kavčič M, Žitnik M, Bučar K, Mihelič A, Štuhec M, Szlachetko J, Cao W, Alonso-Mori R, Glatzel P (2009) Phys Rev Lett 102:143001
65. Young L, Kanter EP, Krässig B, Li Y, March AM, Pratt ST, Santra R, Southworth SH, Rohringer N, Dimauro LF, Doumy G, Roedig CA, Berrah N, Fang L, Hoener M, Bucksbaum PH, Cryan JP, Ghimire S, Glownia JM, Reis DA, Bozek JD, Bostedt C, Messerschmidt M (2010) Nature 466:56

66. Hoszowska J, Kheifets A, Dousse JC, Berset M, Bray I, Cao W, Fennane K, Kayser Y, Kavčič M, Szlachetko J, Szlachetko M (2009) Phys Rev Lett 102:073006

67. Doumy G, Roedig C, Son SK, Blaga CI, DiChiara AD, Santra R, Berrah N, Bostedt C, Bozek JD, Bucksbaum PH, Cryan JP, Fang L, Ghimire S, Glownia JM, Hoener M, Kanter EP, Krässig B, Kuebel M, Messerschmidt M, Paulus GG, Reis DA, Rohringer N, Young L, Agostini P, Dimauro LF (2011) Phys Rev Lett 106:083002

68. Hoszowska J, Dousse JC, Szlachetko J, Kayser Y, Cao W, Jagodzinski P, Kavčič M, Nowak SH (2011) Phys Rev Lett 107:053001

69. Szlachetko J, Sá J (2013) CrystEngComm 15:2583

70. Ferri D, Newton MA, Nachtegaal M (2011) Top Catal 54:1070

71. Hartfelder U, Sá J, van Bokhoven JA (2012) Analyst 137:5374

72. Ferri D, Kumar MS, Wirz R, Eyssler A, Korsak O, Hug P, Weidenkaff A, Newton MA (2010) Phys Chem Chem Phys 12:5634

73. Bressler C, Chergui M (2004) Chem Rev 104:1781

74. Nuernberger P, Wolperta D, Weissc H, Gerber G (2010) Proc Natl Acad Sci USA 107:10366

75. Patterson BD, Sá J, Ichasanow A, Hauri C, Ruchert C, Czekaj I, Gehrig R, Sigg HC, van Bokhoven JA, Pedrini B, Abela R (2011) Chimia 65:323

76. Neutze R, Wouts R, van der Spoel D, Weckert E, Hajdu J (2000) Nature 406:752

77. Huldt G, Szőke A, Hajdu J (2003) J Struct Biol 144:219-227

78. Gaffney KJ, Chapman HN (2007) Science 316:1444

79. Weierstall U, Doak RB, Spence JCH, Starodub D, Shapiro D, Kennedy P, Warner J, Hembree GG, Fromme P, Chapman HN (2008) Exp Fluids 44:657

80. DePonte DP, Doak RB, Hunter M, Liu Z, Weierstall U, Spence JCH (2009) Micron 40:507-509

81. Gañán-Calvo AM, DePonte DP, Herrada MA, Spence JCH, Weierstall U, Doak RB (2010) Small 6:822

82. Bogan MJ, Benner WH, Boutet S, Rohner U, Frank M, Barty A, Seibert MM, Maia F, Marchesini S, Bajt S, Woods B, Riot V, Hau-Riege SP, Svenda M, Marklund E, Spiller E, Hajdu J, Chapman HN (2008) Nano Lett 8:310

83. Bogan MJ, Boutet S, Chapman HN, Marchesini S, Barty A, Benner WH, Rohnerb U, Frank M, Hau-Riegeb SP, Bajt S, Woods B, Seibert MM, Iwang B, Timneanug N, Hajdug J, Schulz J (2010) Aerosol Sci Technol 44:1-6

84. Berner WH, Bogan MJ, Rohner U, Boutet S, Woods B, Frank M (2008) J Aerosol Sci 39:917

85. Liu P, Ziemann PJ, Kittelson DB, McMurry PH (1995) Aerosol Sci Technol 22:293-313

86. Liu P, Ziemann PJ, Kittelson DB, McMurry PH (1995) Aerosol Sci Technol 22:314-324

87. Wexler AS, Johnston MV (2005) Real-time single particle analysis. John Wiley \& Sons, New Jersey, p 365

88. Nash DG, Baer T, Johnston MV (2006) Int J Mass Spectrom 258:2

89. Steele PT, Farquar GR, Martin AN, Coffee KR, Riot VJ, Martin SI, Fergenson DP, Gard EE, Frank M (2008) Anal Chem 80:4583

90. Bogan MJ, Boutet S, Barty A, Benner WH, Frank M, Lomb L, Shoeman R, Starodub D, Seibert MM, Hau-Riege SP, Woods B, Decorwin-Martin P, Bajt S, Schulz J, Rohner U, Iwan B, Timneanu N, Marchesini S, Schlichting I, Hajdu J, Chapman HN (2010) Phys Rev ST Accel Beams 13:094701 